\title{
The Obalon swallowable intragastric balloon in pediatric and adolescent morbid obesity
}

\section{(ㅇ)( $\odot$}

\section{Authors}

Francesco De Peppo ${ }^{1}$, Romina Caccamo², Ottavio Adorisio ${ }^{1}$, Emanuela Ceriati ${ }^{2}$, Paola Marchetti ${ }^{2}$, Antonio Contursi ${ }^{3}$, Arianna Alterio ${ }^{4}$, Claudia Della Corte ${ }^{4}$, Malnia Manco ${ }^{4}$, Valerio Nobili ${ }^{4}$

\section{Institutions}

1 Department of Pediatric Surgery and Transplantation Center, Pediatric Surgery Unit, Bambino Gesù Children's Hospital, Research Institute, Passoscuro, Rome, Italy

2 Department of Pediatric Surgery and Transplantation Center, Hepato-Biliary Surgery Unit, Bambino Gesù Children's Hospital, Research Institute, Passoscuro, Rome, Italy

3 Department of Pediatric Anesthesiology, Bambino Gesù Children's Hospital, Research Institute, Passoscuro, Rome, Italy

4 Hepato-Metabolic Disease Unit and Liver Research Unit, “Bambino Gesu”, Children's Hospital, IRCCS, Rome, Italy

submitted 1.6.2016

accepted after revision $\quad 10.10 .2016$

Bibliography

DOI http://dx.doi.org/10.1055/s-0042-120413 |

Endoscopy International Open 2017; 05: E59-E63

(c) Georg Thieme Verlag KG Stuttgart · New York

ISSN 2364-3722

Corresponding author

Dr. Ottavio Adorisio, Department of Pediatric Surgery, Children's

Hospital "Bambino Gesu” Children's Hospital, via della torre di

Palidoro 50, Palidoro, Rome, Italy

Fax: 0039-06-68593373

o.adorisio@yahoo.it

\section{ABSTRACT}

Background and study aims Incidence of morbid obesity has grown dramatically in the last half century and this phenomenon affects with particular severity the pediatric population. Dietary restrictions and careful programs to improve lifestyle are often ineffective to manage this particular group of patients, due to poor compliance typical of the adolescence. The aim of this study was to evaluate the effectiveness of a new intragastric balloon for treatment of morbidly obese children.

Patients and methods A new swallowable intragastric balloon (Obalon) has been used for the first time in 17 obese children in order to assess its safety and effectiveness in terms of reduction in excess weight. In 9 of 17 children a second balloon was placed 30 to 40 days after the first insertion. All devices were endoscopically removed after a mean time of 18 weeks.

Results In the group of 16 patients who completed the study (1 patient still under treatment) mean weight decreased from $95.8 \pm$ $18.4 \mathrm{Kg}$ to $83.6 \pm 27.1(P<0.05)$. Mean body mass index (BMI) decreased from $35.27 \pm 5.89$ (range 30.4-48) to $32.25 \pm 7.1$ (range 23.5 - 45.7) $(P>0.05)$; mean excess weight, calculated according to Cole's curves for pediatric populations, decreased from $36.2 \pm 15.9$ to $29.4 \pm 18.3 \mathrm{Kg}(P=0.14)$, with an \%EWL of $20.1 \pm 9.8$ (range $2.3-$ 35.1). Waist circumference decreased from $109 \pm 12.3 \mathrm{~cm}$ to $99 \pm$ $10.5 \mathrm{~cm}(P<0.05)$.

Conclusions Obalon can be administered easily without complications, inducing an appreciable weight loss with a statistically significant reduction in BMI and an improvement in associated comorbidities.

\section{Introduction}

Prevalence of pediatric obesity dramatically increased in the last decades especially in western countries [1] but also in developing countries [2,3]. According to the National Health and Nutrition Examination Surveys (NHANES), among 6- to 11-yearold children, prevalence of obesity raised from $4.2 \%$ in the 1960 s, to $19.6 \%$ in $2007-2008$, nearly a 5 -fold increase in 40 years [1]. As a direct consequence, prevalence of the most relevant comorbidities such as hypertension and type II diabetes increased from $2.8 \%$ of the adult population in 1980 to $6.4 \%$ in 2011 [4].

Bariatric surgery in adolescents has gained wide popularity in the last decades and represents an attractive option in patients affected by chronic metabolic syndrome and BMI $>40$ [5-7]. Nevertheless, it should be avoided in younger prepuber- tal children and less invasive forms of treatment favoured in this populationt. Endoscopic treatment by intragastric balloon should be taken into account in treatment of pediatric morbidly obese patients. It doesn't modify gastrointestinal anatomy and can be safely carried out in childhood with a low complication rat [8]. To reduce patient discomfort and invasiveness of treatment by using an intragastric balloon, a new swallowable device (Obalon Therapeutics Inc., San Diego California) has been proposed. Preliminary results in children seem to be encouraging with a significant decrease in body mass index (BMI) and improvement in comorbidities [5, 9].

The aim of this study is to report our experience in patients with the device and to describe technical aspects and practicalities related to the procedure. 


\section{Patients and methods}

From July 2013 to May 2015, 17 children (M/F=6/11) were enrolled. Mean age was $13.6 \pm 2.3$ years (range $9.9-17.1 \mathrm{yr}-$ median $14.1 \mathrm{yr}$ ). All patients were obese, with BMI $>30 \mathrm{~kg}$ associated with obesity-related diseases [dislipedemia, sleep apnea, non-alcoholic steato-hepatitis (NASH), gastroesophageal reflux] or BMI >35 with or without comorbidities. Two patients had slight mental retardation.

Children with hormonal or genetic obesity, presence of an organic disease of the upper gastrointestinal tract, previous gastrointestinal surgery, anti-inflammatory or anticoagulant therapies were excluded.

Fifteen of 17 patients underwent the pill test, which was successfully carried out in 14/15 patients (93.3\%). The last 2 patients were considered unable to swallow the balloon due to slight mental retardation and were directly scheduled for endoscopic insertion.

A balanced diet $(1100 \mathrm{Kcal})$ was always prescribed and regular physical activity strongly recommended to all patients. Patient were followed at 15 days after the procedure and monthly until balloon removal. Patients were treated daily with proton pump inhibitor (lansoprazole $30 \mathrm{mg} /$ day) during the entire treatment period and always advised to avoid drugs harmful to the stomach during the study.

At the end of treatment, balloon removal was performed by upper endoscopy under deep sedation without OT intubation. The balloons were easily deflated by puncture with a sclerotherapy needle and then removed using a standard foreign body forceps.

Patients were divided into 2 groups according to pre-procedure BMI: group A, BMI <35 and group $\mathrm{B}, \mathrm{BMI}>35$.

Data were analyzed using the Statistical Package for Social Sciences 13.0. The paired $t$-test was used to compare the same patients before and after treatment while the Student's $t$-test was employed to determine statistically significant differences between different groups. Results are expressed in terms of mean \pm SD and confidence interval $(\mathrm{Cl}) 95 \%$. Values of $P<0.05$ were considered significant.

Excess weight was calculated according to Cole's curves for pediatric populations because "ideal" BMI varies with age and sex and reaches a value of 25 only at age 18 years [10].

When an endoscopic placement was necessary, deep sedation was performed using a facial mask to ensure adequate oxygenation during the procedure. Endotracheal intubation should be used only in patients considered at higher risk of respiratory distress. Through a large catheter mount a standard 9.8-mm video gastroscope (Olympus GIF Q165) was passed through the facial mask after being inserted into the working channel of a Roth Net standard retriever for removal of round, blunt foreign bodies ( $>$ Fig. 1 ). The pill was inserted into the basket and the net closed to secure the Obalon during its progression through the esophagus into the stomach. Once the capsule had reached the gastric fundus, it was necessary to wait for it to completely unroll before starting balloon inflation according to the usual technique.

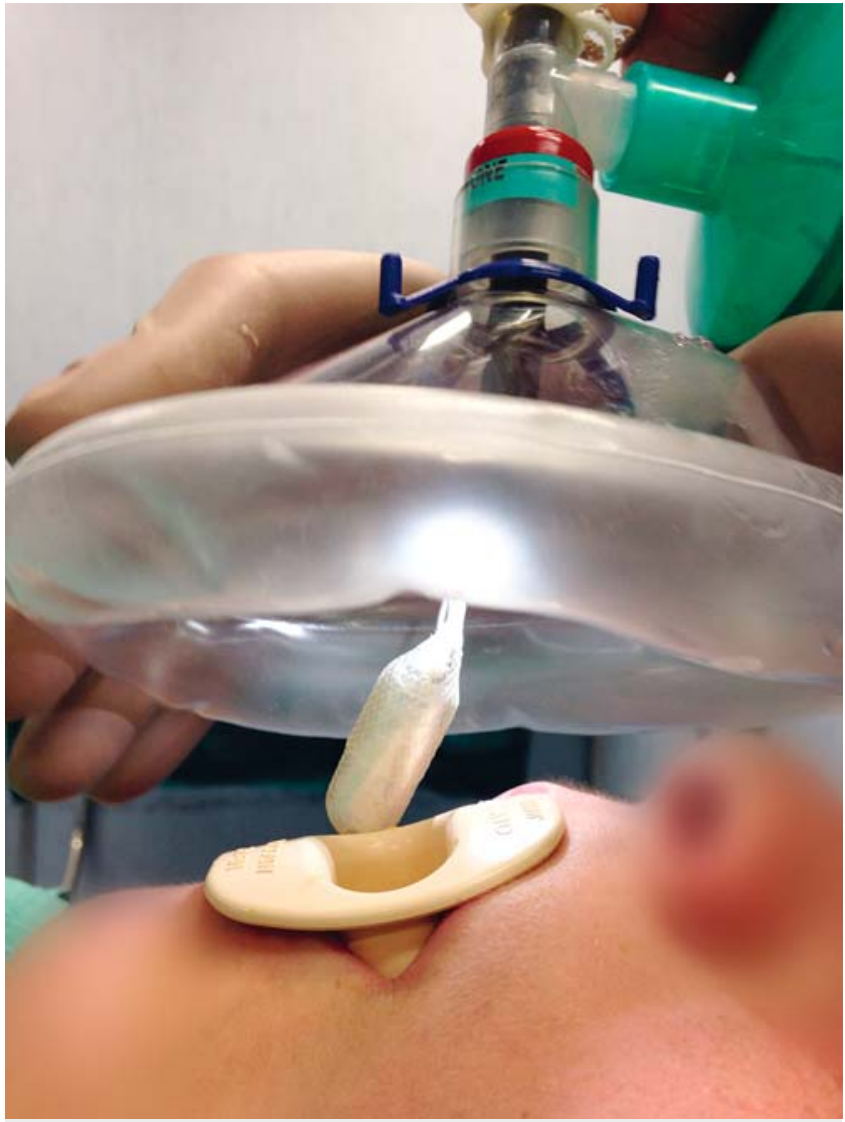

Fig. 1 Endoscopic insertion of the Obalon.

A brief hospitalization ( $<24$ hours) was provided for possible treatment of side effects related to the procedure. Each postoperative symptom was recorded with the eventual use of antispasmodic and/or antiemetic drugs. The protocol was approved by the Ethics Committee of Bambino Gesù Children Hospital (Registry ID 539/RA) and was conformed to the Ethical Guidelines of the Declaration of Helsinki, as revised in 2000. This study was registered on ClinicalTrials.gov (NCT02137330). Written informed consent was obtained from the parents or legal caregivers of all the children.

\section{The device}

Obalon is folded and compressed in a 6 -g dissolvable gelatin capsule connected to a very thin catheter, which is required for inflation of the balloon after it has reached the gastric fundus. A manometer connected to the catheter constantly records the pressure inside the Obalon. After dissolution of the gelatin capsule, the pressure drops below $7 \mathrm{KPa}$, certifying that the balloon has properly unrolled in the stomach. Fluoroscopic control is mandatory before balloon inflation. After complete balloon inflation and stabilization of internal pressure at about $8.3 \mathrm{Kpa}$ to $17.2 \mathrm{Kpa}$, the catheter is detached and removed. Recently a single-dose spray with $250 \mathrm{~mL}$ of nitrogen has been developed, making the procedure easier and executable by a single operator. 
A test with a capsule identical in size and weight to the Obalon but filled with sugar can be administered prior to the procedure to gauge a patient's ability to swallow the pill. Up to 3 balloons can be placed in the same patient according to his/her feeling of satiety.

\section{Results}

Swallowing the first balloon was very simple and fast in 14/15 patients $(93.3 \%)$ who performed the pill test without difficulties, with a mean placement time of 8.5 minutes (range 6-15 minutes) for swallowing and inflation

In 2 patients, aged 11 and 12 years, endoscopy was planned in advance due to a slight mental retardation with subsequent inability to swallow the pill. A 15-year-old girl didn't swallow the Obalon despite several attempts and a previous positive test. In all these cases, endoscopic placement was performed.

To obtain a greater percentage of spontaneous swallowing, we used pharyngeal hypoesthesia with xylocaine spray, improved the taste of the pill with chocolate cream or jam, and inserted the pill into a little bottle of water to avoid direct contact between the catheter and the lips.

In 9 of 17 patients, 40 days after first Obalon insertion, placement of a second balloon was necessary. In these patients, in fact, we recorded a not appreciable reduction in sense of satiety without reduction/arrest of the weight loss curve. In 6 of them (66.6\%), because they were not able to swallow the the deflated balloon, the procedure was performed under deep sedation.

Fifteen patients ( $83 \%$ ) carefully complied with the follow-up instructions while 3 adolescents $(M / F=1 / 2)$ repeatedly deserted controls and, as reported by their parents, did not observe the dietary protocol. One of them did not return to the hospital to remove the balloon and an x-ray of the abdomen, performed at another hospital, showed its spontaneous evacuation after 5 months. In the remaining patients, the balloons were removed under deep sedation without tracheal intubation except in a boy who manifested respiratory distress during induction of anesthesia.

Endoscopic removal was performed after an average of $18.61 \pm 2.36$ weeks (range 12.57-21.57), despite the fact that the treatment period recommended by the Manufacturer is 3 months (about 13 weeks). The purpose of this choice was to increase the effectiveness of treatment, especially in cases treated with 2 balloons. At the time of removal, in 3/9 children who had a second device, we found only 1 device in the stomach for spontaneous evacuation of the second balloon, which was totally unnoticed by 2 of the 3 children. An x-ray study of the abdomen confirmed spontaneous emission of the second Obalon in all these cases. In 2 other cases 1 balloon appeared completely deflated in the gastric fundus and was easily removed (- Fig.2).

\section{Adverse events}

Five of 18 patients reported mild to moderate epigastric pain/ cramping that completely disappeared after 1 day in 3 and after 3 days in 2 patients using a single dose of oral hyoscine butyl-

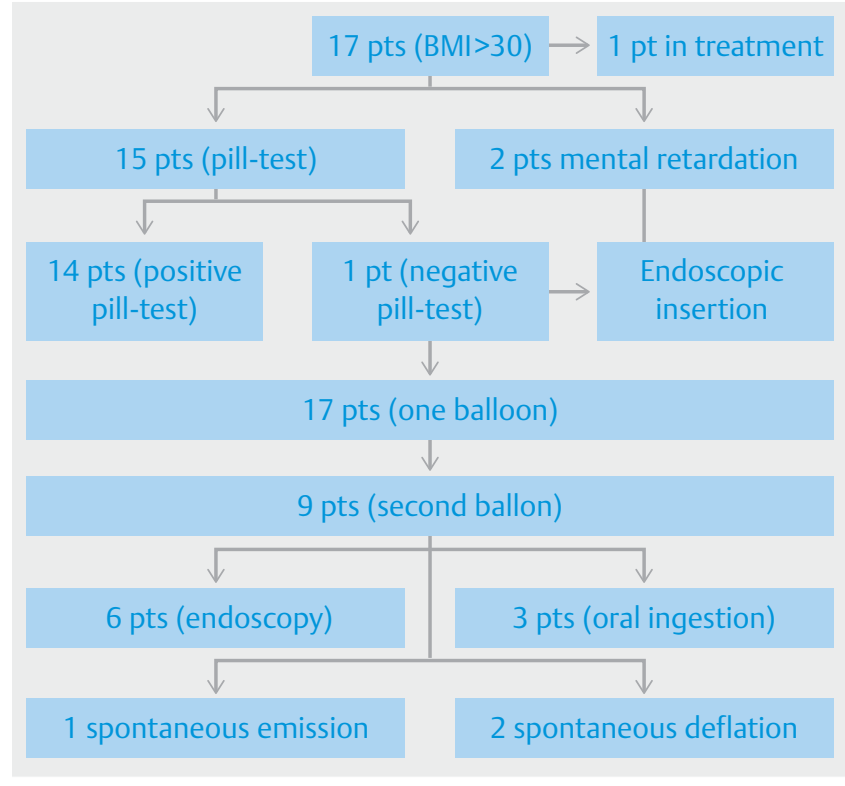

- Fig. 2 Flowchart of the study population.

bromide, associated in 1 case with acetaminophen. A single episode of vomiting occurred in a 15-year-old girl unable to swallow the balloon and resolved with a single dose of intravenous ondansetron. Nausea, recorded in 5 patients, resolved spontaneously after 1 day (4 cases) to 2 days ( 1 case) without medication. Twelve children $(66.6 \%)$ required no medication. In the group of 9 children who underwent a second balloon positioning, side effects were even less common. Mild epigastric pain/cramping was reported by only 2 patients (22.2\%) and a single dose of oral hyoscine butylbromide was administered. In 1 patient, several episodes of hematic vomiting occurred about a month after positioning of the second balloon. An upper endoscopy was promptly performed and ruled out presence of any esophageal or gastric lesions, showing the presence of the balloons in the gastric fundus with no sign of deflation. The otorhinolaryngologist noticed variceal bleeding from the nasal septum with discharge of blood in the stomach during sleep. The balloons were then regularly removed at the end of treatment.

\section{Impact on weight loss}

In the 16 patients who completed the study ( 1 patient still under treatment) mean weight decreased from $9 ., 8 \pm 18,4 \mathrm{Kg}(\mathrm{Cl}$ 86.01 to 105.58$)$ to $83.6 \pm 27.1$ (Cl 69.15 to 98.04$)(P<0.05)$. Mean BMI decreased from $35.27 \pm 5.89(\mathrm{Cl} 32.13$ to 38.40$)$ to $32.25 \pm 7.1$ ( $\mathrm{Cl} 28.46$ to 36.03$)(P>0.05)$; mean weight excess, calculated according to Cole's curves for pediatric populations, decreased from $36.2 \pm 15.9$ (Cl 27.72 to 44.67$)$ to $29.4 \pm 18.3 \mathrm{Kg}$ (Cl 19.64 to 39.15) $(P<0.05)$, with an \%EWL of $20.1 \pm 9.8$ (range $2.3-35.1)$. Waist circumference decreased from $109 \pm 12.3 \mathrm{~cm}$ to $99 \pm 10.5 \mathrm{~cm}(P<0.05)$ ( $\triangleright$ Table 1$)$. Analyzing the results according to starting BMI, a more statistically significant difference $(P<0.05)$ after treatment was found in the 8 patients 
- Table 1 Comparison of preoperative and postoperative patient data.

\begin{tabular}{|c|c|c|c|c|c|c|c|c|c|c|c|c|}
\hline Pz & Età & Peso & BMI & BMI rif & PI & EW & Peso & BMI & BMI rif & PI & EW & $\%$ EWL \\
\hline 1 & 11 aa $3 \mathrm{~m}$ & 75 & 33.78 & 20.55 & 45.62 & 29.38 & 69.5 & 31.3 & 20.89 & 46.37 & 23.13 & 21.27 \\
\hline 2 & 17 aa $2 \mathrm{~m}$ & 94.5 & 34.7 & 24.7 & 67.24 & 26.26 & 88.5 & 32.51 & 24.85 & 67.65 & 20.85 & 23.51 \\
\hline 3 & 16 aa $1 \mathrm{~m}$ & 134.5 & 48 & 23.9 & 66.65 & 67.85 & 138 & 49.48 & 24.19 & 67.76 & 70.24 & -3.52 \\
\hline 4 & 15 aa $2 \mathrm{~m}$ & 110 & 42.53 & 23.94 & 65.17 & 44.83 & 109 & 40.04 & 24.17 & 65.8 & 43.2 & 3.63 \\
\hline 5 & 12 aa $10 \mathrm{~m}$ & 130 & 49.54 & 21.91 & 57.5 & 72.5 & 120 & 45.72 & 22.27 & 58.44 & 61.56 & 15.08 \\
\hline 6 & 11 aa $4 \mathrm{~m}$ & 91.6 & 39.13 & 20.89 & 48.9 & 42.7 & 85.9 & 36.7 & 21.22 & 49.67 & 36.23 & 15.15 \\
\hline 7 & 14 aa $7 \mathrm{~m}$ & 103 & 34.61 & 22.96 & 68.32 & 34.68 & 95 & 31.93 & 23.29 & 70.51 & 24.49 & 29.38 \\
\hline 8 & 16 aa $4 \mathrm{~m}$ & 110 & 39.44 & 24.54 & 68.43 & 41.57 & 109.5 & 39.26 & 24.54 & 68.43 & 41.07 & 1.2 \\
\hline 9 & 14 aa $1 \mathrm{~m}$ & 106 & 37.56 & 23.34 & 65.87 & 40.13 & 102 & 36.1 & 23.66 & 66.77 & 32.23 & 12.21 \\
\hline 10 & 13 aа & 89.5 & 35.85 & 22.58 & 56.36 & 33.14 & 80 & 32 & 22.98 & 57.36 & 22.64 & 31.68 \\
\hline 11 & 9 aa $11 \mathrm{~m}$ & 85.5 & 38 & 19.86 & 44.68 & 40.82 & 82 & 36.4 & 20.29 & 45.65 & 36.35 & 10.95 \\
\hline 12 & 13 aa $1 \mathrm{~m}$ & 86 & 34.45 & 22.58 & 56.36 & 29.64 & 78 & 31.24 & 22.98 & 57.36 & 20.64 & 30.36 \\
\hline 13 & 14 aa $4 \mathrm{~m}$ & 78 & 30.09 & 23.44 & 60.49 & 9.51 & 61 & 23.53 & 23.66 & 61.32 & 0.32 & 96.63 \\
\hline 14 & 16 aa $4 \mathrm{~m}$ & 78 & 31.64 & 24.54 & 60.48 & 17.52 & 66 & 26.8 & 24.54 & 61.26 & 4.74 & 72.94 \\
\hline 15 & 12 aa $5 \mathrm{~m}$ & 75 & 30.04 & 21.56 & 53.82 & 21.18 & 62.5 & 25.04 & 21.91 & 54.69 & 7.81 & 63.12 \\
\hline 16 & 11 a $10 \mathrm{~m}$ & 86 & 30.11 & 20.74 & 59.23 & 26.77 & 81 & 28.36 & 20.74 & 59.23 & 21.77 & 18.67 \\
\hline
\end{tabular}

BMI, body mass index; BMI Rif, body mass index corrected per age; IW, ideal weight; EW, excess weight

- Table 2 Comparison of preoperative and postoperative data from patients with BMI>35.

\begin{tabular}{|c|c|c|c|c|c|c|c|c|c|c|c|c|}
\hline $\mathbf{P z}$ & Età & Peso & BMI & BMI rif & PI & EW & Peso & BMI & BMI rif & PI & EW & \% EWL \\
\hline 1 & 11 aa $3 \mathrm{~m}$ & 75 & 33.78 & 20.55 & 45.62 & 29.38 & 69.5 & 31.3 & 20.89 & 46.37 & 23.13 & 21.27 \\
\hline 2 & 17 aa $2 \mathrm{~m}$ & 94.5 & 34.7 & 24.7 & 67.24 & 26.26 & 88.5 & 32.51 & 24.85 & 67.65 & 20.85 & 23.51 \\
\hline 3 & 14 aa $7 \mathrm{~m}$ & 103 & 34.61 & 22.96 & 68.32 & 34.68 & 95 & 31.93 & 23.29 & 70.51 & 24.49 & 29.38 \\
\hline 4 & 13 aa $1 \mathrm{~m}$ & 86 & 34.45 & 22.58 & 56.36 & 29.64 & 78 & 31.24 & 22.98 & 57.36 & 20.64 & 30.36 \\
\hline 5 & 14 аa $4 \mathrm{~m}$ & 78 & 30.09 & 23.44 & 60.49 & 9.51 & 61 & 23.53 & 23.66 & 61.32 & 0.32 & 96.63 \\
\hline 6 & 16 aa $4 \mathrm{~m}$ & 78 & 31.64 & 24.54 & 60.48 & 17.52 & 66 & 26.8 & 24.54 & 61.26 & 4.74 & 72.94 \\
\hline 7 & 12 aa $5 \mathrm{~m}$ & 75 & 30.04 & 21.56 & 53.82 & 21.18 & 62.5 & 25.04 & 21.91 & 54.69 & 7.81 & 63.12 \\
\hline 8 & 11 a $10 \mathrm{~m}$ & 86 & 30.11 & 20.74 & 59.23 & 26.77 & 81 & 28.36 & 20.74 & 59.23 & 21.77 & 18.67 \\
\hline
\end{tabular}

BMI, body mass index; BMI Rif, body mass index corrected per age; IW, ideal weight; EW, excess weight

with preoperative $\mathrm{BMI}<35$ (Group A) ( Table 2 ) compared with those with $\mathrm{BMI}>35$ (Group B) $(0,0004$ vs 0.49$)$ ( $>$ Table 3 ).

\section{Discussion}

Intragastric balloon therapy is currently considered a valuable option for morbidly obese patients unresponsive to behavioral and nutritional treatment who are not eligible for surgery or who don't accept surgery.

Different types of intragastric balloons have been used in the past in pediatric and adolescent patients with various degrees of obesity [10-12]. The most widely used is the BioEnterics intragastric balloon (BIB; Allergan, Irvine, CA), a silicone rub- ber device introduced in 1999. Complications of the BIB are gastric ulcers, gastric erosions, esophagitis, spontaneous deflation, persistent vomiting, gastroesophageal reflux, and abdominal pain. Some reports also exist of gastric perforations, small bowel obstructions, and significant gastric dilation [13-15].

Given these concerns, we tested the Obalon device and observed that, in the majority of cases ( $82 \%$ ), patients were able to swallow it without sedation and general anesthesia was required only at the end of treatment during balloon removal. Furthermore the Obalon device can be used starting at a lower threshold $\mathrm{BMI}(>30)$ respect to BIB or other intragastric balloons because of its lower side effect and complication rates. These aspects make the Obalon device useful and safe in pa- 
- Table 3 Comparison between preoperative and postoperative data from patients with $\mathrm{BMI}<35$.

\begin{tabular}{|c|c|c|c|c|c|c|c|c|c|c|c|c|}
\hline $\mathrm{Pz}$ & Età & Peso & BMI & BMI rif & PI & EW & Peso & BMI & BMI rif & PI & EW & $\%$ EWL \\
\hline 1 & 16 aa $1 \mathrm{~m}$ & 134.5 & 48 & 23.9 & 66.65 & 67.85 & 138 & 49.48 & 24.19 & 67.76 & 70.24 & -3.52 \\
\hline 2 & 15 aa $2 \mathrm{~m}$ & 110 & 42.53 & 23.94 & 65.17 & 44.83 & 109 & 40.04 & 24.17 & 65.8 & 43.2 & 3.63 \\
\hline 3 & 12 aa $10 \mathrm{~m}$ & 130 & 49.54 & 21.91 & 57.5 & 72.5 & 120 & 45.72 & 22.27 & 58.44 & 61.56 & 15.08 \\
\hline 4 & 11 aа $4 \mathrm{~m}$ & 91.6 & 39.13 & 20.89 & 48.9 & 42.7 & 85.9 & 36.7 & 21.22 & 49.67 & 36.23 & 15.15 \\
\hline 5 & 16 aа $4 \mathrm{~m}$ & 110 & 39.44 & 24.54 & 68.43 & 41.57 & 109.5 & 39.26 & 24.54 & 68.43 & 41.07 & 1.2 \\
\hline 6 & 14 aa $1 \mathrm{~m}$ & 106 & 37.56 & 23.34 & 65.87 & 40.13 & 102 & 36.1 & 23.66 & 66.77 & 32.23 & 12.21 \\
\hline 7 & 13 аа & 89.5 & 35.85 & 22.58 & 56.36 & 33.14 & 80 & 32 & 22.98 & 57.36 & 22.64 & 31.68 \\
\hline 8 & 9 aa $11 \mathrm{~m}$ & 85.5 & 38 & 19.86 & 44.68 & 40.82 & 82 & 36.4 & 20.29 & 45.65 & 36.35 & 10.95 \\
\hline
\end{tabular}

tients with moderate obesity with or without comorbidities, both in childhood and in adolescence.

At the beginning of our experience with Obalon in a pediatric population, we considered as a primary goal the feasibility and safety of the procedure as well as its effectiveness in terms of weight loss. For that reason, during the first year of the study, we enrolled patients with a wide range of BMI (30-50). After a complete analysis of preliminary results, we decided to treat only patients with first-degree obesity and BMI between 30 and 35. Results obtained from the current series confirm the effectiveness of treatment in these children. For these reasons, our patients were enrolled in the study despite having BMI that was lower than the value recommended by the European Guidelines on surgery of severe obesity [16].

We think that all obese pediatric patients should have the necessary tools to reverse the tendency to gain weight and the intragastric balloon may be the starting point on this path.

The results of our study demonstrated that Obalon device can be easily administered without anesthesia in the majority of patients (83\%) and within 3 months it induces significant weight loss. Use of the Obalon device for more than 13 weeks, as suggested by the manufacturer, resulted in spontaneous deflation in 3 of our patients and unnoticed and spontaneous emission of the balloon in 2 of 3 patients. Despite this, the device can be considered a helpful tool for management of subjects with Class I obesity and ensure an appreciable weight loss, particularly in children and adolescents with $\mathrm{BMI}<35$.

\section{Competing interests}

None

\section{References}

[1] Tauber M. Obesity and overweight of children and adolescents. Rev Prat 2015; 65: 1263
[2] Wang Y, Lobstein T. Worldwide trends in childhood overweight and obesity. Int J Pediatr Obes 2006; 1: 11-25

[3] Kelishadi R. Childhood overweight, obesity, and the metabolic syndrome in developing countries. Epidemiol Rev 2007; 29: 62 - 76

[4] Skoczen S, Wojcik M, Fijorek K et al. Expression of the central obesity and Type 2 Diabetes mellitus genes is associated with insulin resistance in young obese children. Exp Clin Endocrinol Diabetes 2015; 123: $252-259$

[5] Vandenplas Y, Bollen P, De Langhe K et al. Intragastric balloons in adolescents with morbid obesity. Eur J Gastroenterol Hepatol 1999; 11: $243-245$

[6] Freedman DS, Mei Z, Srinivasan SR et al. Cardiovascular risk factors and excess adiposity among overweight children and adolescents: the Bogalusa Heart Study. J Pediatr 2007; 150: 12 - 17, e2

[7] Wang G, Dietz WH. Economic burden of obesity in youths aged 6 to 17 years: 1979-1999. Pediatrics 2002; 109: E81-E86

[8] Inge TH, Krebs NF, Garcia VF et al. Bariatric surgery for severely overweight adolescents: concerns and recommendations. Pediatrics 2004; 114: $217-223$

[9] Cunneen SA. Review of meta-analytic comparisons of bariatric surgery with a focus on laparoscopic adjustable gastric banding. Surg Obes Relat Dis 2008; 4: 47-55

[10] Nobili V, Corte CD, Liccardo D et al. Obalon intragastric balloon in the treatment of paediatric obesity: a pilot study. Pediatr Obes 2015; 10 : e1-4

[11] Genco A, Bruni T, Doldi SB et al. BioEnterics Intragastric Balloon: The Italian Experience with 2,515 Patients. Obes Surg 2005; 15: 1161 1164

[12] Brooks JI, Srivastava ED, Mathus-Vliegen EM. One-year adjustable intragastric balloons: results in 73 consecutive patients in the U. K. Obes Surg 2014; 24: 813-819

[13] Genco A1, Dellepiane D, Baglio G et al. Adjustable intragastric balloon vs non-adjustable intragastric balloon: case-control study on complications, tolerance, and efficacy. Obes Surg 2013; 23: 953-958

[14] De Peppo F, Di Giorgio G, Germani M et al. BioEnterics intragastric balloon for treatment of morbid obesity in Prader-Willi syndrome: specific risks and benefits. Obes Surg 2008; 18: 1443-1449

[15] Kirby DF, Wade JB, Mills PR et al. A prospective assessment of the Garren-Edwards Gastric Bubble and bariatric surgery in the treatment of morbid obesity. Am Surg 1990; 56: 575-580

[16] Fried M, Yumuk V, Oppert JM et al. Interdisciplinary European guidelines on metabolic and bariatric surgery. Obes Surg 2014; 24: 42-55 